\title{
Neochlorogenic acid enhances the antitumor effects of pingyangmycin via regulating TOP2A
}

\author{
JIANHUAN CHE ${ }^{1}$, TONGXIA ZHAO ${ }^{1}$, WEN LIU ${ }^{2}$, SHI CHEN $^{1}$, \\ GUANGYU YANG ${ }^{3}$, XINYAN LI $^{1}$ and DONGLING LIU ${ }^{1}$ \\ ${ }^{1}$ Department of Oral and Maxillofacial Surgery, Hospital of Stomatology, Jilin University; \\ ${ }^{2}$ Department of Cardiovascular Medicine, The First Hospital of Jilin University; \\ ${ }^{3}$ Department of Otorhinolaryngology Head and Neck Surgery, Hospital of Stomatology, \\ Jilin University, Changchun, Jilin 130021, P.R. China
}

Received March 18, 2020; Accepted July 13, 2020

DOI: $10.3892 / \mathrm{mmr} .2020 .11797$

\begin{abstract}
Neochlorogenic acid (NCA), a natural compound found in honeysuckle, possesses prominent anti-inflammatory and antitumor effects. Pingyangmycin (PYM) induces DNA damage and has been used for the treatment of oral and maxillofacial tumors. Oral care serves an important role in promoting wound healing during chemotherapy in patients with oral squamous cell carcinoma (OSCC). Therefore, the present study aimed to analyze the effects of NCA and PYM on OSCC cells and to investigate the potential underlying mechanism. Reverse transcription-quantitative PCR and western blotting were conducted to analyze the expression levels of DNA topoisomerase II $\alpha$ (TOP2A) in different OSCC cell lines. TOP2A-overexpression cells were constructed via transfection of TOP2A-overexpression plasmids. Following NCA or PYM treatment, cell proliferation was assessed using Cell Counting Kit- 8 and colony formation assays, whereas cell apoptosis and the cell cycle distribution were assessed via TUNEL staining and flow cytometry, respectively. In addition, the expression levels of apoptosis- and cell cycle-related proteins were detected via western blotting. Moreover, co-immunoprecipitation (Co-IP) was conducted to determine whether TOP2A interacted with CDK1. The results of the present study indicated that NCA treatment significantly enhanced the suppressive effects of PYM on OSCC cell proliferation and apoptosis. The results also indicated that PYM arrested the cell cycle in the $\mathrm{G}_{0} / 1$ by regulating cyclin dependent kinase 1 (CDK1)/cyclin B1, which was enhanced by the cotreatment of NCA and PYM. In addition, NCA and PYA treatment altered the expression levels of apoptosis-related
\end{abstract}

Correspondence to: Dr Dongling Liu, Department of Oral and Maxillofacial Surgery, Hospital of Stomatology, Jilin University, 1500 Tsinghua Road, Changchun, Jilin 130021, P.R. China

E-mail: donglingliuu@163.com

Key words: neochlorogenic acid, pingyangmycin, DNA topoisomerase II $\alpha$, oral squamous cell carcinoma, cell cycle proteins. The Co-IP assay indicated that TOP2A interacted with CDK1. Moreover, TOP2A overexpression significantly reversed the effects of NCA and PYM treatment on OSCC cell proliferation and apoptosis. In addition, NCA significantly decreased PYM-induced toxicity in normal oral epithelial cells. In conclusion, the results of the present study suggested that NCA may promote the inhibitory effects of PYM in OSCC via TOP2A.

\section{Introduction}

Pingyangmycin (PYM) has been widely used to treat head and neck squamous cell carcinoma, the cytotoxic effects of which depend on its ability to bind to iron and directly damage DNA, subsequently promoting cell death (1-4). In addition to inhibiting tumor growth, PYM affects cell apoptosis, chronic inflammation and angiogenesis $(2,5,6)$. PYM also exerts a similar mechanism as bleomycin in inducing cell cycle arrest and cell apoptosis (2). A previous study suggested that PYM promoted cell apoptosis, potentially via activating the p53-dependent signaling pathway (7). PYM, a novel, hydrophilic, antitumor glycopeptide antibiotic, is produced by Streptomycetes in the soil of Pingyang county (2). In addition, neochlorogenic acid (NCA), as one of main components of Cyclocarya paliurus, was suggested to be involved in suppressing cell apoptosis by regulating the mitogen-activated protein kinase/AKT signaling pathway (8). Moreover, NCA, as a phenolic in pectinase-treated Prunus mume fruit concentrate, exerts antitumor effects via promoting cell cycle arrest at the $\mathrm{S}$ phase and cell apoptosis via the mitochondrial-dependent apoptotic pathway, but does not demonstrate cytotoxicity in normal cells (9). A previous study has also indicated that NCA may be involved in the anticancer effects of Leonurus sibiricus extract, which are closely associated with DNA damage (10). The effects of phenolic compounds on DNA damage may be attributed to mutagenic activity, possibly by intercalating with DNA (11).

Topoisomerases function as important ribozymes that primarily regulate the topological structure of DNA by catalyzing the formation or disconnection of phosphodiester bonds (12). DNA topoisomerase II $\alpha$ (TOP2A), which is a target 
of several anticancer drugs, can be damaged or suppressed, which hinders the replication and transcription of DNA, further promoting cell death (13). The abnormalities in TOP2A caused by anticancer drugs induce DNA double-strand breaks and lead to cell apoptosis by stabilizing the TOP2A cleavage complex (14). TOP2A is necessary for cell replication and is expressed at elevated levels during cell proliferation (14). In a previous study, compared with normal cells, cancer cells displayed upregulated expression levels of topoisomerase, independent of other factors $(15,16)$. Oral squamous cell carcinoma (OSCC) is the most common type of malignant oral and maxillofacial tumor (17). Therefore, the present study aimed to analyze the effects of NCA and PYM on OSCC cells and to investigate the potential underlying mechanism.

\section{Materials and methods}

Cell lines and reagents. HOK (human normal oral keratinocytes), A-253, HSC-4, CAL-27 and SCC-4 cells lines (The Cell Bank of Type Culture Collection of the Chinese Academy of Sciences) were cultured in DMEM (Hyclone; Cytiva) supplemented with $10 \%$ FBS (Biowest), $100 \mathrm{U} / \mathrm{ml}$ penicillin and $100 \mu \mathrm{g} / \mathrm{ml}$ streptomycin at $37^{\circ} \mathrm{C}$ with $5 \% \mathrm{CO}_{2}$. PYM (Harbin Pharmaceutical Group Co., Ltd.) was dissolved in $1 \mathrm{mg} / \mathrm{ml}$ PBS to make a stock solution.

Reverse transcription-quantitative PCR (RT-qPCR). Cells were washed twice with PBS and total RNA was extracted using TRIzol ${ }^{\circledR}$ (Invitrogen; Thermo Fisher Scientific, Inc.). The concentration of RNA was detected using a spectrophotometer. Total RNA was reverse transcribed into cDNA using a ReverTra Aceq PCR RT kit at $37^{\circ} \mathrm{C}$ for $15 \mathrm{~min}$ (Toyobo Life Science). Subsequently, qPCR was performed using the FastStart Universal SYBR Green Master mix (Sigma-Aldrich; Merck KGaA). The following primer sequences were used for the qPCR: TOP2A forward, 5'-CATTGAAGACGCTTC GTTATGG-3' and reverse, 5'-CAGAAGAGAGGGCCAGTT GTG-3'; and $\beta$-actin forward, 5'-ATAGCACAGCCTGGA TAGCAACGTAC-3' and reverse, 5'-CACCTTCTACAATGA GCTGCGTGTG-3'. The following thermocycling conditions were used for the qPCR: Initial denaturation for $1 \mathrm{~min}$ at $95^{\circ} \mathrm{C}$; followed by 40 cycles at $95^{\circ} \mathrm{C}$ for $30 \mathrm{sec}$ and $60^{\circ} \mathrm{C}$ for $40 \mathrm{sec}$; and the reaction was then maintained at $72^{\circ} \mathrm{C}$ for $5 \mathrm{~min}$. TOP2A mRNA expression levels were quantified using the $2^{-\Delta \Delta \mathrm{Cq}}$ method (18).

Western blotting. Cells were washed with precooled PBS and total protein was extracted from cells using RIPA lysis buffer (Invitrogen; Thermo Fisher Scientific, Inc.). Total protein was quantified using a BCA assay. Proteins (40 $\mu \mathrm{g}$ protein/lane) were separated via $12 \%$ SDS-PAGE and transferred onto PVDF membranes, which were blocked with $5 \%$ skim milk for $2 \mathrm{~h}$ at room temperature. The membranes were incubated with the following primary antibodies at $4^{\circ} \mathrm{C}$ overnight: Anti-TOP2A (1:10,000; cat. no. ab52934; Abcam), anti-CDK1 (1:2,000; cat. no. ab32094; Abcam), anti-Bax (1:1,000; cat. no. ab32503; Abcam), anti-caspase-3 (1:500; cat. no. ab13847; Abcam), anti-Bcl-2 (1:1,000; cat. no. ab32124; Abcam), anti-Cyclin B1 (1:1,000; sc-245; Santa Cruz Biotechnology, Inc.) and anti-GAPDH (1:5,000; cat. no. ab8245; Abcam) Following the primary antibody incubation, the membranes were rinsed three times with TBS- $0.05 \%$ Tween- 20 at $37^{\circ} \mathrm{C}$ and then incubated with a horseradish peroxidase-conjugated goat anti-rabbit IgG (1:10,000; cat. no. ab6721; Abcam) or rabbit anti-mouse IgG (1:10,000; cat. no. ab6728; Abcam) secondary antibody at $37^{\circ} \mathrm{C}$ for $2 \mathrm{~h}$. Protein bands were visualized using an ECL reagent (EMD Millipore). Protein expression was semi-quantified using ImageJ software version 1.46 (National Institutes of Health) with GAPDH as the loading control.

Cell transfection. TOP2A overexpression plasmids [pcDNA3.1(+)-TOP2A] were constructed and packaged by Shanghai GenePharma Co., Ltd. Cells $\left(1.5 \times 10^{6}\right.$ cells/well $)$ were transfected with $0.5 \mu \mathrm{g} / \mu \mathrm{l}$ TOP2A overexpression plasmids or empty plasmids as the control group using Lipofectamine ${ }^{\circledR} 2000$ (Invitrogen; Thermo Fisher Scientific, Inc.) at $37^{\circ} \mathrm{C}$ for $24 \mathrm{~h}$. Subsequently, the cells were used for subsequent experiments.

Cell Counting Kit-8 (CCK-8) assay. Cell viability was assessed using a CCK-8 kit (cat. no. CK04; Dojindo Molecular Technologies, Inc.), according to the manufacturer's protocol. A total of $8 \times 10^{3}$ cells/well were seeded into 96 -well plates at $37^{\circ} \mathrm{C}$ with $5 \% \mathrm{CO}_{2}$. Cells were treated with $10 \mu \mathrm{g} / \mathrm{ml}$ PYM or $20 \mu \mathrm{M} \mathrm{NCA}$ at $37^{\circ} \mathrm{C}$ for $24 \mathrm{~h}$. Subsequently, $10 \mu \mathrm{l} \mathrm{CCK}-8$ solution was added to each well and incubated at $37^{\circ} \mathrm{C}$ for $4 \mathrm{~h}$. The absorbance was detected at a wavelength of $450 \mathrm{~nm}$ using a microplate reader (EnSpire; PerkinElmer, Inc.).

Colony formation assay. Cells were quantified using a blood counting chamber. Briefly, cells were seeded into a $10 \mathrm{ml}$ petri-dish $\left(2 \times 10^{2}\right.$ cells $)$ containing $10 \mathrm{ml} \mathrm{DMEM}$ and $10 \% \mathrm{FBS}$, and were cultured for 14 days at $37^{\circ} \mathrm{C}$ with $5 \% \mathrm{CO}_{2}$. When visible colonies ( $>50$ cells) appeared in the petri-dishes, the supernatant was discarded, and cells were washed twice with PBS. Cells were fixed with $5 \mathrm{ml} 10 \%$ methanol at $4^{\circ} \mathrm{C}$ for $10 \mathrm{~min}$. Following $0.1 \%$ crystal violet staining (Sigma-Aldrich; Merck KGaA) at $37^{\circ} \mathrm{C}$ for $20 \mathrm{~min}$, the number of cell colonies formed was counted under a light microscope (magnification, x20; CKX31SF; Olympus Corporation).

TUNEL staining. Cells were fixed with $4 \%$ paraformaldehyde at $37^{\circ} \mathrm{C}$ for $20 \mathrm{~min}$ and washed twice with PBS. Subsequently, cells were treated using $0.2 \%$ Triton $\mathrm{X}-100$ at $37^{\circ} \mathrm{C}$ for $5 \mathrm{~min}$ and washed twice with PBS. Cells were incubated with the prepared TUNEL reaction liquid at $37^{\circ} \mathrm{C}$ for $1 \mathrm{~h}$. Following incubation, cells were washed with PBS and stained with $80 \mu \mathrm{l}$ $20 \% \mathrm{DAB}$ at $37^{\circ} \mathrm{C}$ for $10 \mathrm{~min}$. Cells were subsequently stained with $5 \mu \mathrm{g} / \mathrm{ml}$ hematoxylin at $37^{\circ} \mathrm{C}$ for $5 \mathrm{sec}$. Dehydrated transparent neutral gum was used to mount the sections. The cells were then observed under a fluorescent microscope (magnification, $x 200$ ) in six randomly selected fields of view to observe TUNEL positive cells.

Cell cycle analysis. The cell cycle distribution was detected using a Cell Cycle kit (EZCell ${ }^{\mathrm{TM}}$ Cell Cycle Analysis kit; BioVision, Inc.). Cells were seeded ( $1 \times 10^{5}$ cells $\left./ \mathrm{ml}\right)$ into 6 -well plates. Following PYM or NCA treatment for $24 \mathrm{~h}$ at $37^{\circ} \mathrm{C}$, cells were washed twice with precooled PBS and fixed with precooled $70 \%$ ethanol for $24 \mathrm{~h}$ at $4^{\circ} \mathrm{C}$. Cells were washed twice with PBS and incubated with $400 \mu \mathrm{l}$ PI $(50 \mu \mathrm{g} / \mathrm{ml})$ and 
A

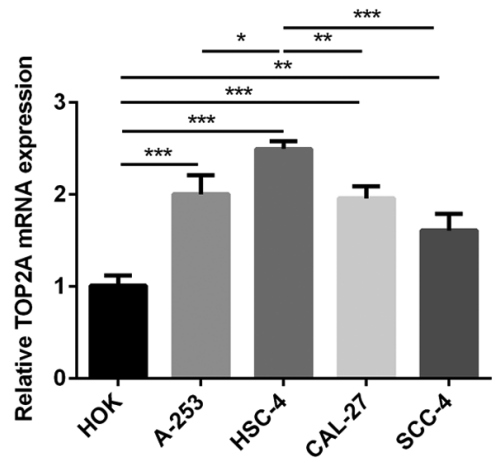

B

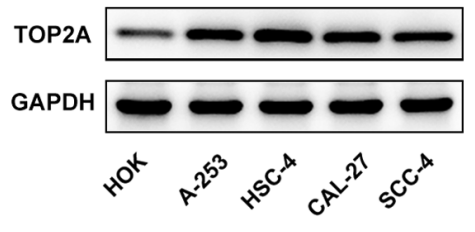

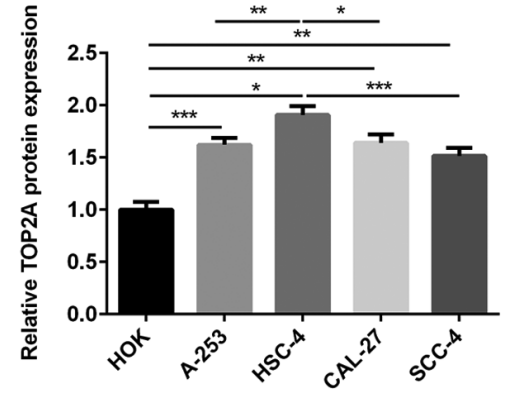

Figure 1. Expression levels of TOP2A in different OSCC cell lines. TOP2A (A) mRNA and (B) protein expression levels in OSCC cell lines. ${ }^{*} \mathrm{P}<0.05$, ${ }^{* *} \mathrm{P}<0.01$ and ${ }^{* * *} \mathrm{P}<0.001$. TOP2A, DNA topoisomerase II $\alpha$; OSCC, oral squamous cell carcinoma.

$100 \mu \mathrm{l}$ RaseA $(100 \mu \mathrm{g} / \mathrm{ml})$ for $1 \mathrm{~h}$ in the dark at $4^{\circ} \mathrm{C}(\mathrm{BD}$ Biosciences). Cell cycle distribution was analyzed via flow cytometry (LSR-II; BD Biosciences) and analyzed using FlowJo version 10 software (FlowJo LLC).

Co-immunoprecipitation (Co-IP). Cells were collected and washed twice with PBS. Cell lysate was prepared using $500 \mu \mathrm{l}$ RIPA lysis buffer (Invitrogen; Thermo Fisher Scientific, Inc.), centrifuged at $24,148.8 \times \mathrm{g}$ for $10 \mathrm{~min}$ at $4^{\circ} \mathrm{C}$ and part of the supernatant was used to perform western blotting analysis as the input. Then, $1 \mu \mathrm{g}$ anti-TOP2A (1:10,000; cat. no. ab52934; Abcam) and anti-rabbit IgG (1:1,000; ab172730; Abcam; negative control) primary antibodies were incubated with the remaining supernatant at $4^{\circ} \mathrm{C}$ overnight. Following the incubation, $10 \mu \mathrm{l}$ Protein A agarose beads (Cell Signaling Technology, Inc.) were added to the remaining supernatant to capture antigen-antibody complexes at $4^{\circ} \mathrm{C}$ for $4 \mathrm{~h}$. Then, the supernatant was centrifuged for $3 \mathrm{~min}$ at $1,509.3 \mathrm{x}$ g at $4^{\circ} \mathrm{C}$. Immunoprecipitation was performed by conducting western blotting according to the aforementioned protocol.

Statistical analysis. Statistical analysis was performed using GraphPad Prism 6 software (GraphPad Software, Inc.). Data are presented as the mean $\pm \mathrm{SD}$ of $\geq 3$ experimental repeats. Comparisons among multiple groups were analyzed using one-way ANOVA and a Tukey's post hoc test. $\mathrm{P}<0.05$ was considered to indicate a statistically significant difference.

\section{Results}

Expression levels of TOP2A in different OSCC cell lines. TOP2A expression levels were analyzed in HOK, A-253, HSC-4, CAL-27 and SCC-4 cells via RT-qPCR and western blotting (Fig. 1). Compared with HOK cells, TOP2A expression levels were significantly upregulated in OSCC cell lines. Moreover, the expression levels of TOP2A in HSC-4 cells were significantly increased compared with the other OSCC cell lines. Therefore, HSC-4 cells were used for subsequent experiments.

NCA increases the inhibitory effects of PYM in OSCC via TOP2A. RT-qPCR and western blotting were performed to assess the transfection efficacy of the TOP2A overexpression plasmid (Fig. 2A and B). TOP2A expression levels were significantly downregulated by PYM or NCA treatment compared with the control group (Fig. 2C). In addition, treatment with PYM or NCA significantly suppressed HSC-4 cell proliferation, as determined by conducting CCK- 8 and colony formation assays (Fig. 3A-C). The combination of NCA and PYM treatment significantly increased the inhibitory effects induced by either treatment alone on cell proliferation. Moreover, TOP2A overexpression significantly reversed the suppressive effects of NCA and PYM on cell proliferation. Therefore, the results suggested that NCA may enhance the inhibitory effects of PYM on HSC-4 cell proliferation by regulating TOP2A.

NCA enhances PYM-induced OSCC cell apoptosis via TOP2A. The TUNEL staining results indicated that NCA enhanced PYM-induced OSCC cell apoptosis (Fig. 4A and B). In addition, the combination of PYM and NCA treatment significantly increased cell cycle arrest in the $\mathrm{G}_{0} /{ }_{1}$ and reduced cell levels in the S phase compared with the PYM or NCA groups (Fig. 4C and D), indicating that the combination of PYM and NCA treatment may suppress the transition from $\mathrm{G}_{1}$ to $\mathrm{S}$ phase. To analyze the mechanisms underlying PYMand NCA-mediated regulation of the cell cycle, the expression levels of cell cycle-related proteins were detected via western blotting (Fig. 5A). The results indicated that the expression levels of CDK1 and cyclin B1 were significantly downregulated in the PYM and NCA groups compared with the control group. Moreover, compared with the control group, the expression levels of the anti-apoptotic protein Bcl-2 were significantly downregulated, but the expression levels of the proapoptotic proteins, Bax and caspase-3, were significantly upregulated in the PYM and NCA groups (Fig. 5A). NCA enhanced the effects of PYM treatment on cell cycle arrest and cell apoptosis, potentially by regulating $\mathrm{CDK} 1 /$ cyclin $\mathrm{B} 1$ expression levels and the mitochondrial-mediated apoptotic pathway in a TOP2A-dependent manner. Furthermore, when the supernatant was incubated with an anti-TOP2A antibody, CDK1 was detected in the immunoprecipitation complex, which indicated that TOP2A may interact with CDK1 (Fig. 5B).

Effects of NCA on normal oral epithelial cells. Subsequently, whether NCA exerted protective effects against PYM-induced oral epithelial cell injury was investigated. The CCK- 8 assay and TUNEL staining results indicated that NCA markedly decreased 
A

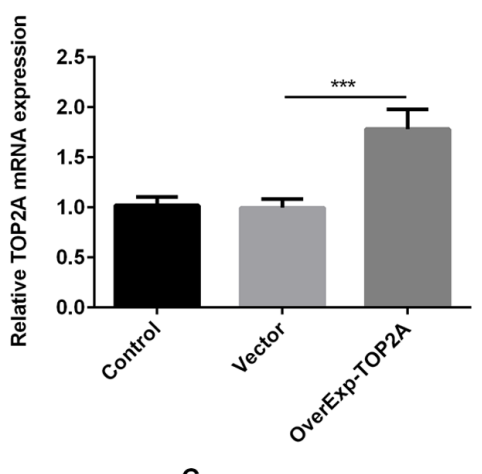

C
B

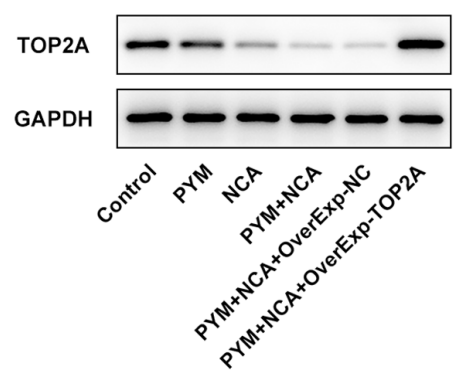

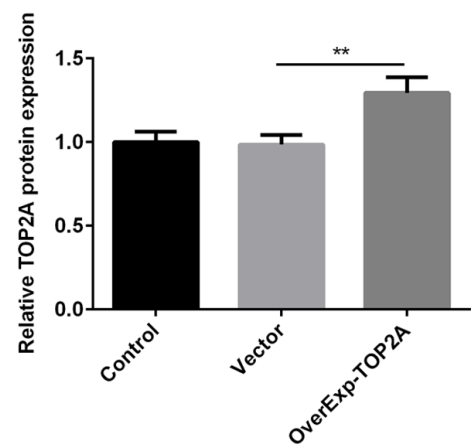

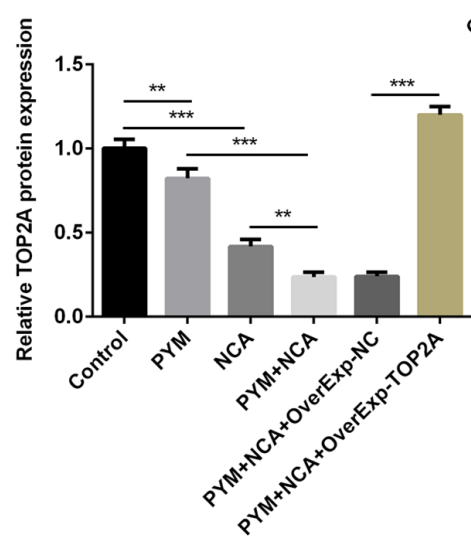

Figure 2. Transfection efficiency of TOP2A overexpression, and the effect of PYM and NCA on TOP2A expression. TOP2A (A) mRNA and (B) protein expression levels following TOP2A overexpression. (C) Effect of PYM and NCA on TOP2A expression levels. ${ }^{* *} \mathrm{P}<0.01$ and ${ }^{* * *} \mathrm{P}<0.001$. TOP2A, DNA topoisomerase II $\alpha$; PYM, pingyangmycin; NCA, neochlorogenic acid; OverExp, overexpression; NC, negative control.
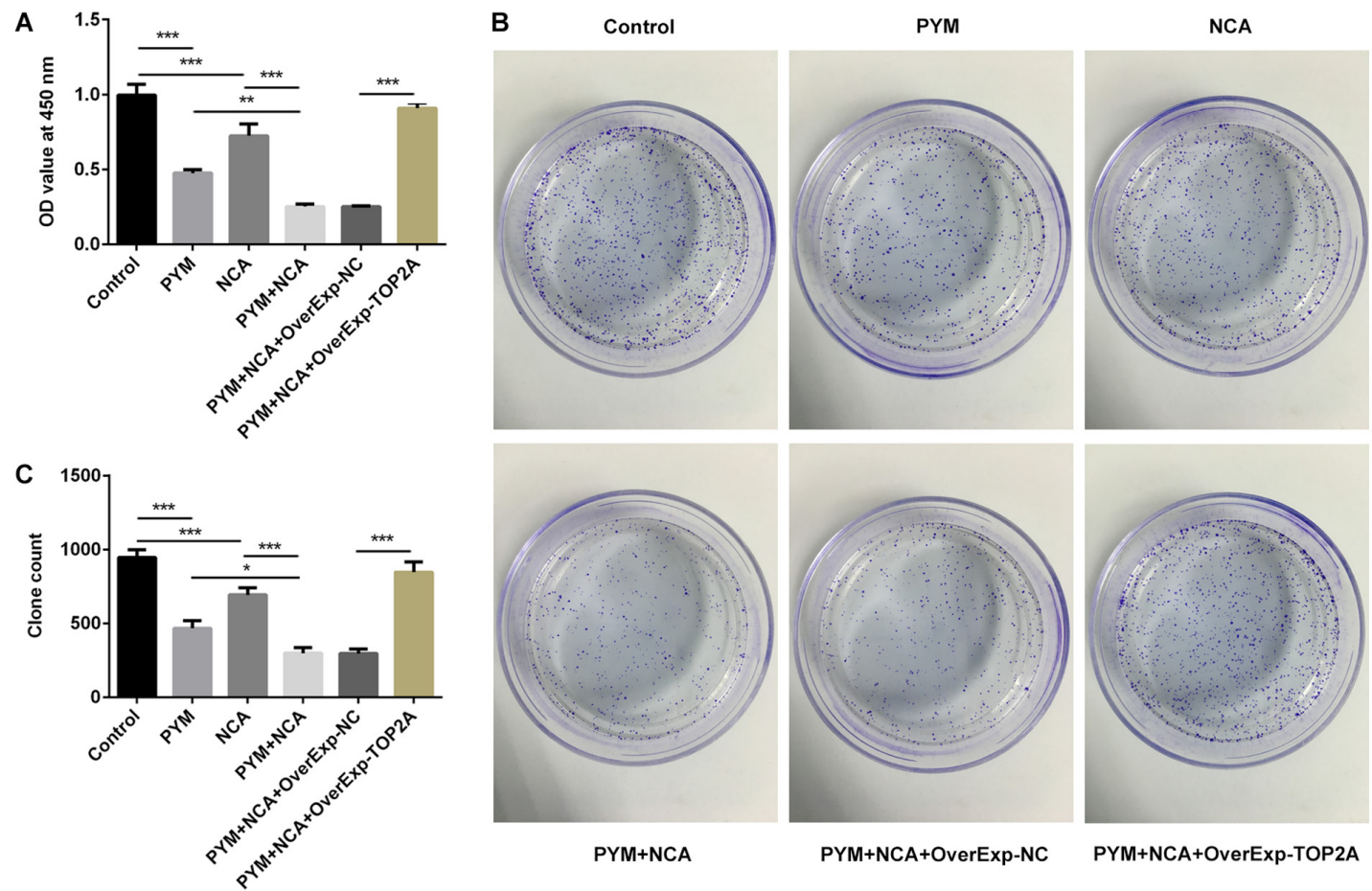

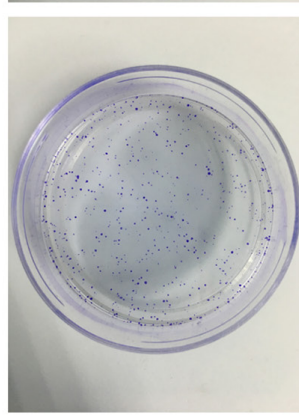

PYM+NCA

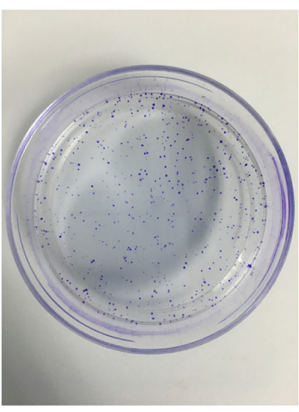

PYM+NCA+OverExp-NC

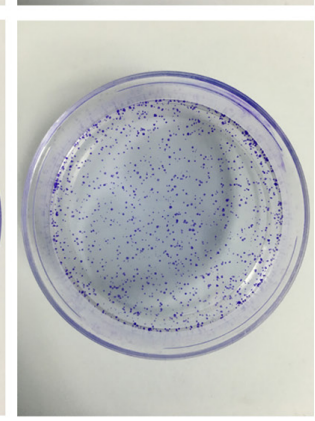

PYM+NCA+OverExp-TOP2A

Figure 3. Effect of PYM and NCA on oral squamous cell carcinoma cell proliferation. Cell proliferation was assessed by performing (A) Cell Counting Kit-8 and (B) colony formation assays. (C) Colony count from part B. Each colony had $>50$ cells. Magnification, $\mathrm{x} 20 .{ }^{*} \mathrm{P}<0.05,{ }^{* *} \mathrm{P}<0.01$ and ${ }^{* * * *} \mathrm{P}<0.001$. PYM, pingyangmycin; NCA, neochlorogenic acid; OD, optical density; NC, negative control; OverExp, overexpression.

the toxicity of PYM in normal oral epithelial cells (Fig. 6A-C). The results also demonstrated that in normal cells, the combination of PYM and NCA significantly reduced cell apoptosis compared with PYM alone (Fig. 6B and C). Furthermore, NCA decreased PYM-induced normal cell injury by regulating the cell cycle and apoptotic pathways (Fig. 6D and E). In HOK cells, NCA significantly upregulated TOP2A expression compared with the PYM group (Fig. 6D and E), whereas NCA displayed 
A

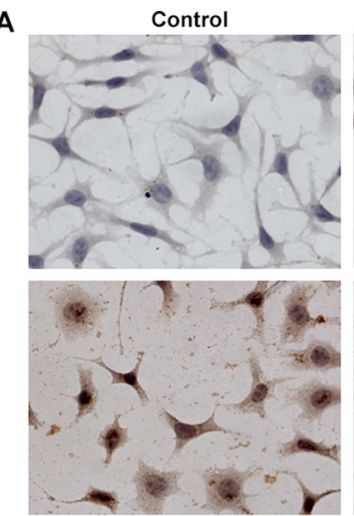

$\mathrm{PYM}+\mathrm{NCA}$

C

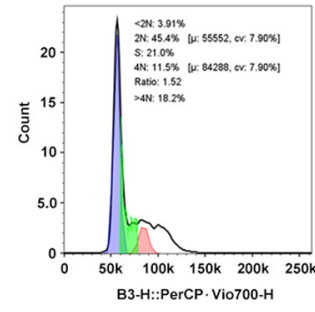

PYM+NCA

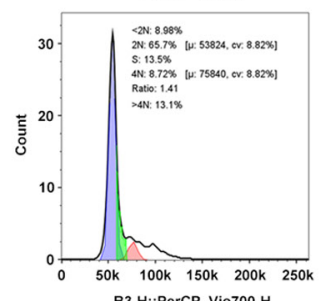

PYM

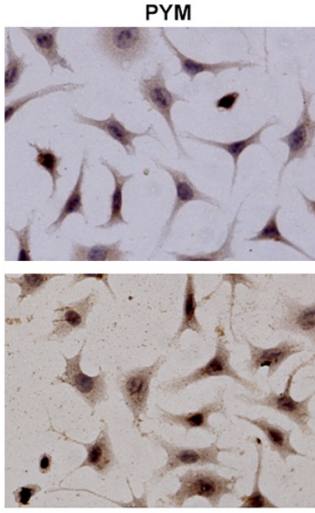

PYM+NCA+OverExp-NC

PYM

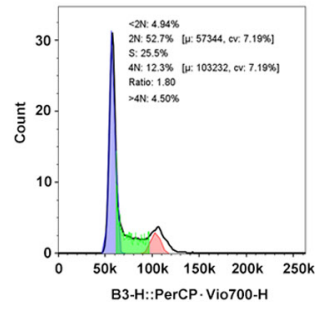

PYM+NCA+OverExp-NC

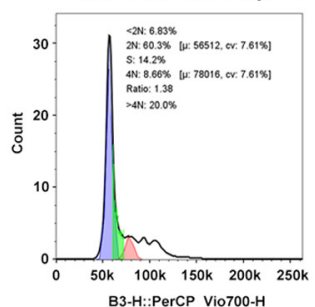

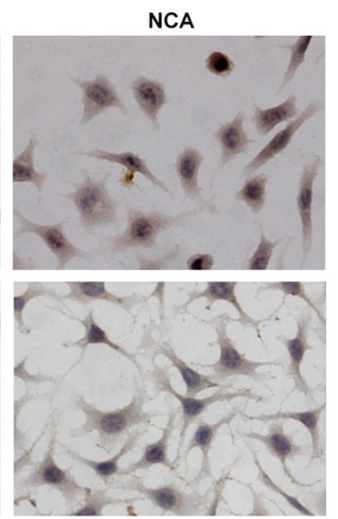

PYM+NCA+OverExp-TOP2A

NCA

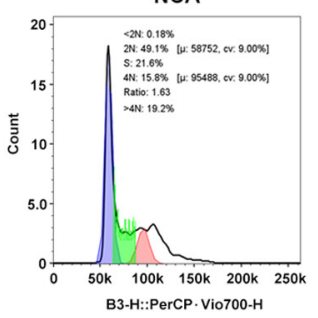

PYM+NCA+OverExp-TOP2A

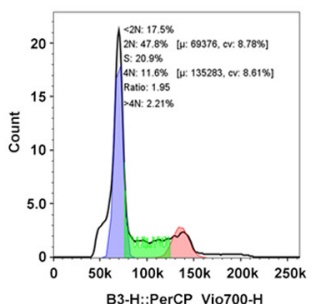

B

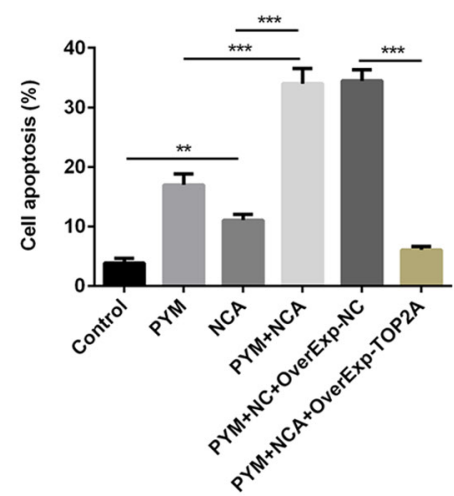

D

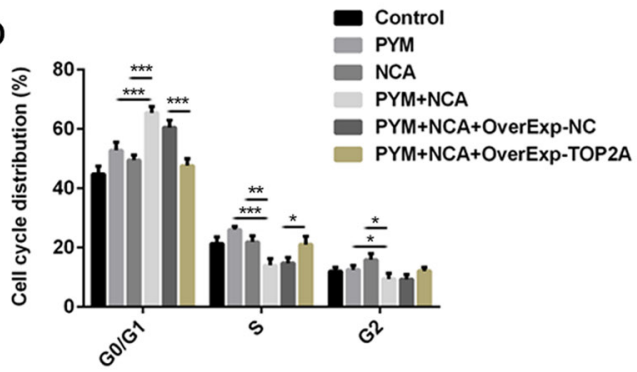

Figure 4. Effect of PYM and NCA on oral squamous cell carcinoma cell apoptosis and cell cycle distribution. (A) Cell apoptosis was assessed via TUNEL staining. Magnification, x200. (B) Semi-quantification of the results from part (A). (C) The cell cycle distribution was assessed via flow cytometry. (D) Quantification of cell cycle analysis from part (C). ${ }^{*} \mathrm{P}<0.05,{ }^{* *} \mathrm{P}<0.01$ and ${ }^{* * *} \mathrm{P}<0.001$. PYM, pingyangmycin; NCA, neochlorogenic acid; NC, negative control; OverExp, overexpression.

the opposite effects in HSC-4 cells (Fig. 2C). Therefore, NCA may regulate TOP2A expression in human normal oral cells and OSCC cells via different mechanisms.

\section{Discussion}

PYM, as one of the main chemotherapy drugs in preoperative induction chemotherapy for patients with OSCC, has achieved good efficacy; however, the drug presents with increased side effects, such as oral mucositis $(19,20)$. The present study indicated that the combined treatment of PYM and NCA displayed improved, synergistic effects over the suppression of HSC-4 cell proliferation. OSCC is the most common malignant type of oral and maxillofacial tumor worldwide $(21,22)$. PYM induces a common side effect of chemotherapy, oral mucositis, which can cause patients oral mucosal pain (23). Therefore, oral care has been hypothesized to serve an important role in enhancing the wound healing process during chemotherapy (24). A previous study suggested that drugs derived from natural products may provide important therapeutic effects for numerous types of human disease (25).

Honeysuckle is an effective compound that is used in a number of mouthwashes (26). Moreover, honeysuckle contains numerous types of organic acid active ingredients, among which, chlorogenic acid has been thoroughly studied (27-29). NCA, an isomer of chlorogenic acid, displays significant anti-inflammatory, antitumor and immune-promoting effects (30-32). In the present study, the expression levels of TOP2A were significantly upregulated in OSCC cells compared with HOK cells. TOP2A and CDK1 expression levels have been reported to be upregulated in certain types of cancer, where expression is negatively associated with patient survival (33-35). In addition, TOP2A inhibited the incorrect attachment of microtubules and kinetochores, and was involved in suppressing tumor cell proliferation (16,36). Moreover, the TOP2A signaling pathway was also reported to mediate cell cycle arrest (16). The present study revealed that NCA promoted PYM-mediated cell cycle arrest at the $\mathrm{G}_{0 / 1}$ phase via TOP2A. The checkpoint in the $\mathrm{G}_{1} / \mathrm{S}$ phase determines whether the cell proliferates (37). Under normal conditions, $\mathrm{G}_{1}$ arrest prevents damaged DNA from replication and helps to repair the damaged DNA (37). CDK1 serves an important role in determining mitotic progression (38). CDK1/cyclin complexes phosphorylate substrates that are involved in triggering centrosome separation, Golgi dynamics, nuclear envelope breakdown and chromosome condensation during the $\mathrm{G}_{2}$ phase and early mitosis (37). Once 
A
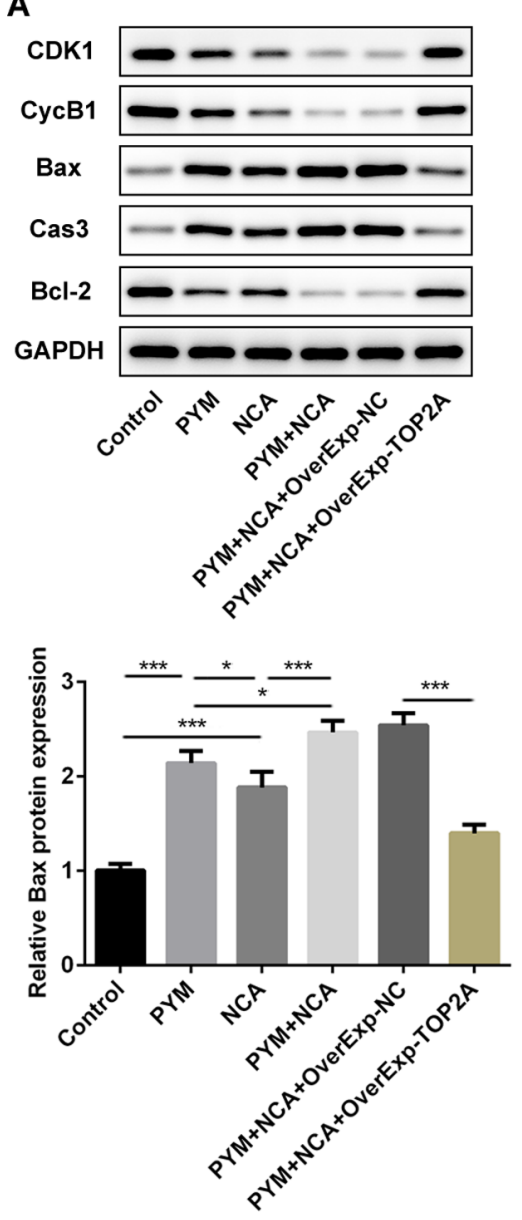

B
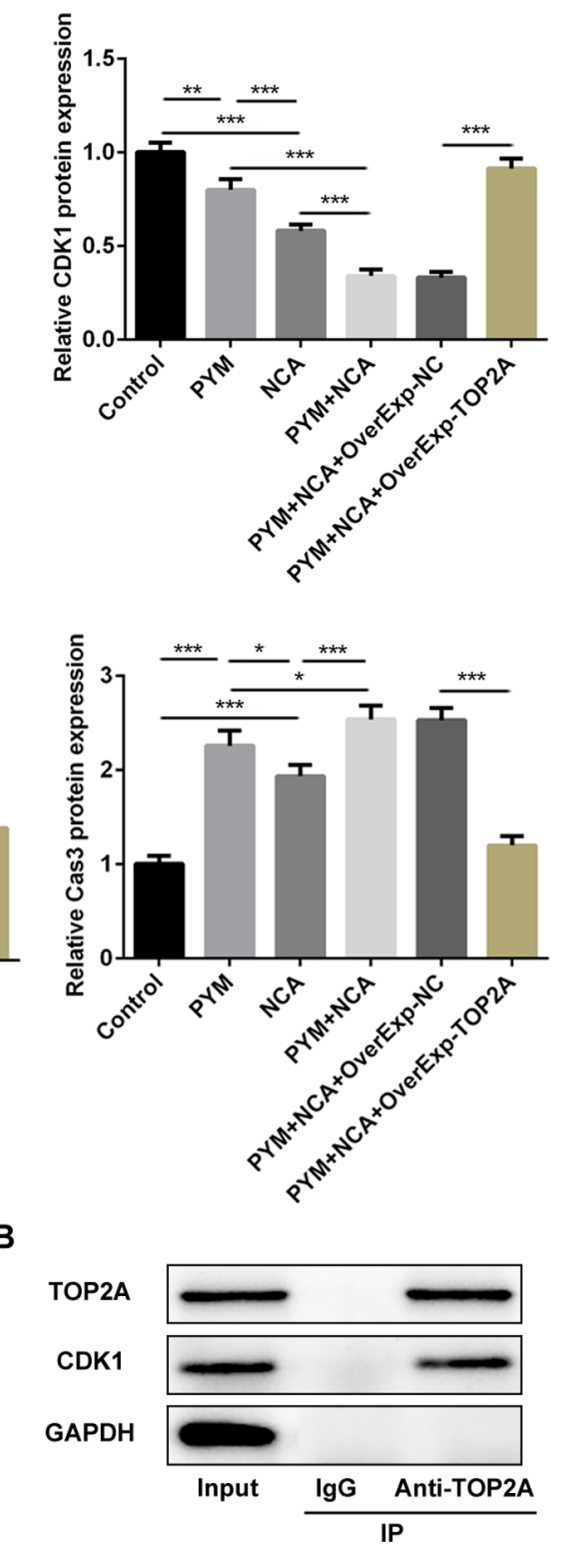
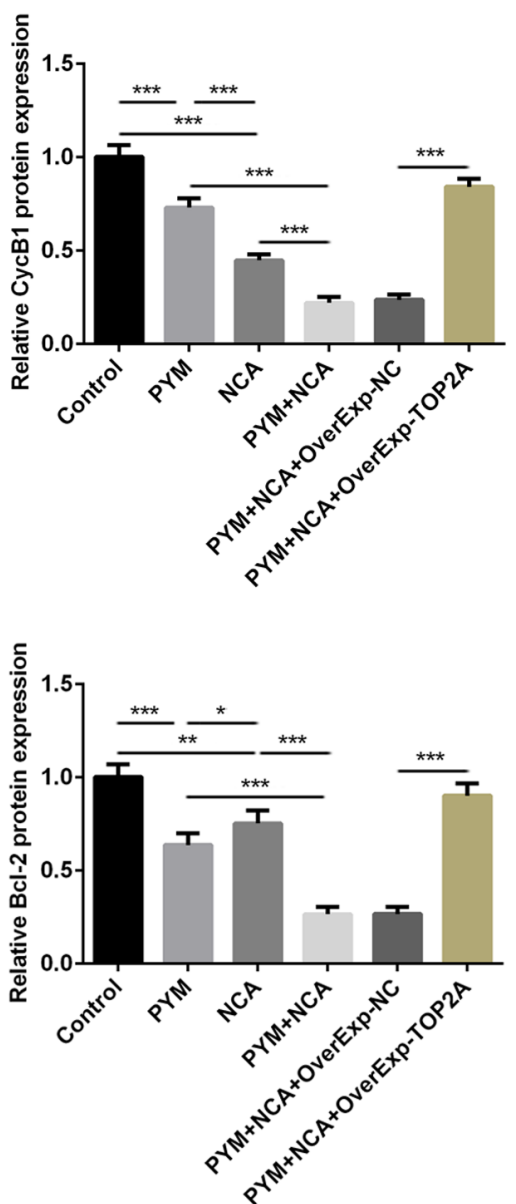

Figure 5. Effect of PYM and NCA on the expression of cell apoptosis- and cell cycle-associated proteins. (A) Protein expression levels of cell cycle- and cell apoptosis-associated proteins. (B) Co-immunoprecipitation was performed to assess the interaction between TOP2A and CDK1. ${ }^{*} \mathrm{P}<0.05,{ }^{* *} \mathrm{P}<0.01$ and ${ }^{* * *} \mathrm{P}<0.001$. PYM, pingyangmycin; NCA, neochlorogenic acid; TOP2A, DNA topoisomerase II $\alpha$; NC, negative control; OverExp, overexpression; CDK1, cyclin dependent kinase 1; CycB1, cyclin B1; Cas3, caspase 3.

CDK1 is inactivated during cell injury, the cells are arrested at the $\mathrm{G}_{2}$ checkpoint to facilitate cell repair (37). However, a previous study has reported that the absence of CDK1 compensated the CDK2 functions by driving cells into the S phase (39). The results of the present study indicated that NCA and PYM treatment may arrest cells in the $\mathrm{G}_{1}$ phase, potentially by decreasing CDK1 and cyclin B expression levels. A previous study revealed that downregulated endogenous lysine acetyltransferase $2 \mathrm{~A}$ expression levels promoted $\mathrm{G}_{1} / \mathrm{S}$ transition, partially via downregulating CDK1 expression in an E2F transcription factor 1-dependent manner (40). Furthermore, CDK1 has been reported to be involved in $\mathrm{G}_{1}$ arrest (41). Previously, it was demonstrated that the promotion of $\mathrm{G}_{1} / \mathrm{S}$ transition occurred via the interaction of ZNFX1 antisense RNA 1 with the CDK1/cyclin B complex (42). The present study indicated that NCA treatment enhanced the antitumor effects of PYM by arresting the cell cycle in the $\mathrm{G}_{0 / 1}$ phase in a TOP2A-mediated manner. In addition, both NCA and PYM treatment induced OSCC cell apoptosis, which was partially mediated via regulating the TOP2A-mediated mitochondrial-dependent apoptotic pathway. For normal cells, NCA did not inhibit proliferation, but moderately promoted it, and at the same time reduced PYM-induced apoptosis. It has been reported that NCA exerts antitumor effects in a dose-dependent manner in vitro and suppresses tumor growth in vivo in human gastric carcinoma cells (32). Moreover, NCA reduces ROS production and suppresses mTOR/PI3K/Akt signaling (32). NCA also possesses strong free radical scavenging and antioxidant activities (43). Furthermore, NCA has been reported to activate the nuclear factor ery throid 2-related factor 2 signaling pathway and induce 5'AMP-activated protein kinase phosphorylation (44). Research has demonstrated that Apocynum venetum tea extracts 

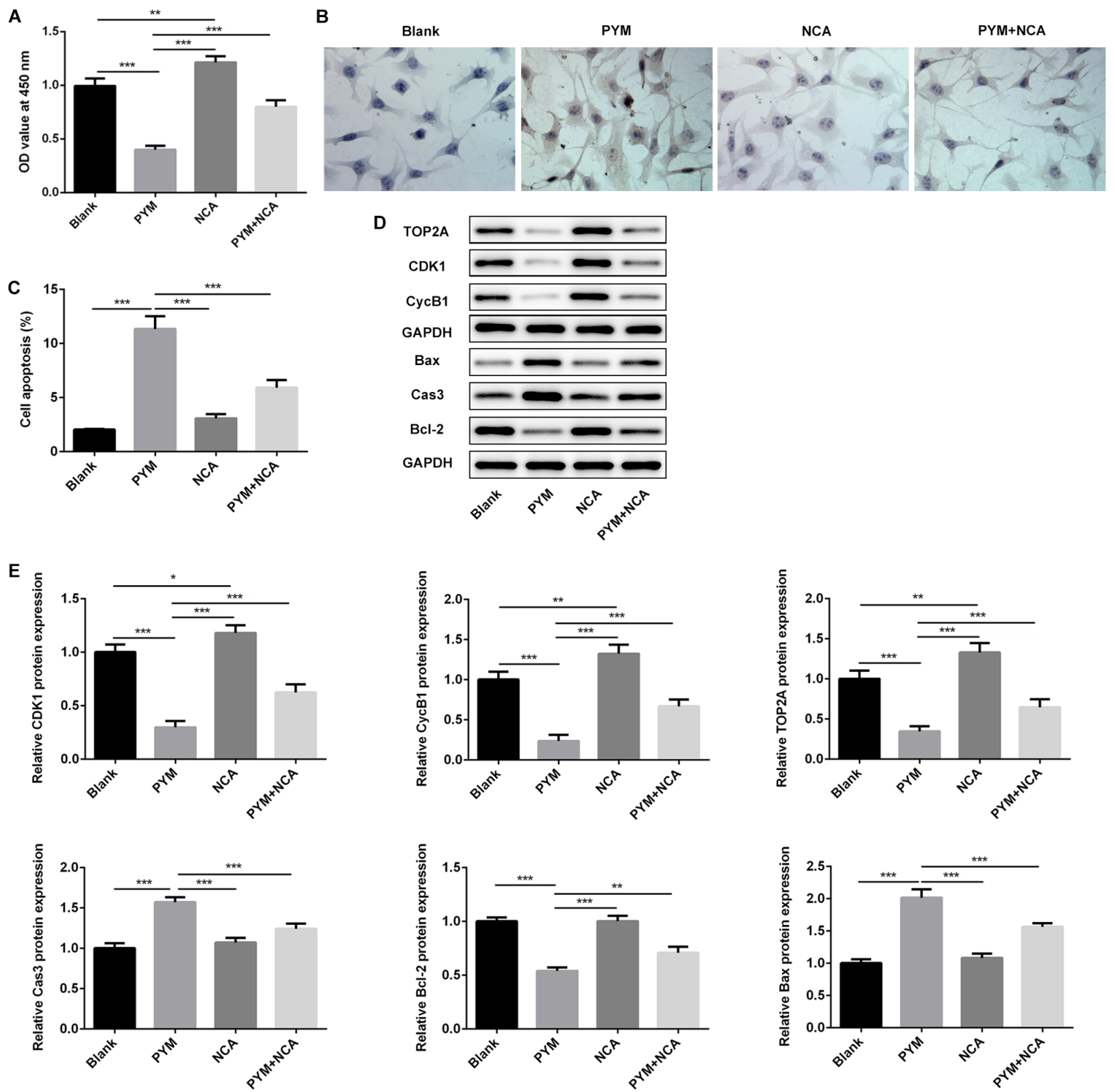

Figure 6. Effect of PYM and NCA on normal cells. (A) Cell proliferation was assessed by conducting the Cell Counting Kit-8 assay. (B) Cell apoptosis was assessed via TUNEL staining. Magnification, x200. (C) Semi-quantification of the results presented in part (B). (D) Expression levels of cell cycle- and apoptosis-associated proteins. (E) Semi-quantification of the expression levels presented in part (D). ${ }^{*} \mathrm{P}<0.05,{ }^{* *} \mathrm{P}<0.01$ and ${ }^{* * * *} \mathrm{P}<0.001$. PYM, pingyangmycin; NCA, neochlorogenic acid; OD, optical density; TOP2A, DNA topoisomerase II $\alpha$; CDK1, cyclin dependent kinase 1; CycB1, cyclin B1; Cas3, caspase 3.

(AVTEs), which contain NCA, exert antioxidation effects and promote cell survival in 293T cells, whereas in HepG2 human hepatoma cells, AVTEs display antitumor effects potentially by inducing cell apoptosis (45). Collectively, the aforementioned studies and the present study indicated that NCA could display different effects between normal cells and cancer cells via different mechanisms. The present study indicated that NCA displays antioxidant activities by promoting HOK cell survival, as indicated by the CCK-8 assay and TUNEL staining results. A previous study indicated that in etomoxir-induced oxidative stress, TOP2A expression was downregulated (46). In addition, the dose of NCA used in the present study displayed different effects in HOK and HSC-4 cells. The Co-IP results suggested that CDK1 interacted with TOP2A in HSC-4 cells, which indicated that NCA enhanced the antitumor effects of PYM partly via regulating the interaction of $\mathrm{CDK} 1$ and TOP2A. TOP2A and CDK1 expression levels are upregulated and are associated with low survival in some types of cancer, such as adrenocortical (47) and hepatocellular carcinoma (48). By constructing a protein-protein interaction network, a previous study identified a potential relationship between CDK1 and TOP2A (49-51). In addition to regulating the cell cycle, CDKs possess a broad range of biological functions, including an involvement in DNA damage repair and interactions with other proteins to regulate tumor growth (52-54). In conclusion, the results of the present study suggested that NCA may enhance the antitumor effects of PYM by regulating TOP2A. Moreover, NCA may reduce the toxicity of PYM in normal oral epithelial cells. Therefore, the use of NCA may enhance the therapeutic effects of PYM chemotherapy in patients with OSCC. 


\section{Acknowledgements}

Not applicable.

\section{Funding}

No funding was received.

\section{Availability of data and materials}

The datasets used and/or analyzed during the current study are available from the corresponding author on reasonable request.

\section{Authors' contributions}

JC and DL made substantial contributions to the conception and design of the study, acquired, analyzed and interpreted the data, and drafted and revised the manuscript for important intellectual content; TZ, WL, SC, GY and XL performed the experiments and interpreted the data. All authors read and approved the final manuscript.

\section{Ethics approval and consent to participate}

Not applicable.

\section{Patient consent for publication}

Not applicable.

\section{Competing interests}

The authors declare that they have no competing interests.

\section{References}

1. Gong JH, Liu XJ, Li Y and Zhen YS: Pingyangmycin downregulates the expression of EGFR and enhances the effects of cetuximab on esophageal cancer cells and the xenograft in athymic mice. Cancer Chemother Pharmacol 69: 1323-1332, 2012.

2. He Y, Lan Y, Liu Y, Yu H, Han Z, Li X and Zhang L: Pingyangmycin and bleomycin share the same cytotoxicity pathway. Molecules 21: 862, 2016.

3. Chen J and Stubbe J: Bleomycins: Towards better therapeutics. Nat Rev Cancer 5: 102-112, 2005.

4. Tai KW, Chang YC, Chou LS and Chou MY: Cytotoxic effect of pingyangmycin on cultured KB cells. Oral Oncol 34: 219-223, 1998.

5. Sun ML, Wang CM and Wen YM: Anticancer effects of Pingyangmycin-activated carbon nanoparticles against human oral squamous carcinoma Tca8113 and BcaCD885 cell lines in vitro. Hua Xi Kou Qiang Yi Xue Za Zhi 28: 257-260, 2010 (In Chinese).

6. Zhang L, Chen F, Zheng J, Wang H, Qin X and Pan W: Chitosan-based liposomal thermogels for the controlled delivery of pingyangmycin: Design, optimization and in vitro and in vivo studies. Drug Deliv 25: 690-702, 2018.

7. Tu JB, Li QY, Jiang F, Hu XY, Ma RZ, Dong Q, Zhang H, Pattar P and Li SX: Pingyangmycin stimulates apoptosis in human hemangioma-derived endothelial cells through activation of the p53 pathway. Mol Med Rep 10: 301-305, 2014.

8. Ning ZW, Zhai LX, Peng J, Zhao L, Huang T, Lin CY, Chen WH, Luo Z, Xiao HT and Bian ZX: Simultaneous UPLC-TQ-MS/MS determination of six active components in rat plasma: Application in the pharmacokinetic study of Cyclocarya paliurus leaves. Chin Med 14: 28, 2019.
9. Cho HD, Kim JH, Won YS, Moon KD and Seo KI: Inhibitory effects of pectinase-treated Prunus mume fruit concentrate on colorectal cancer proliferation and angiogenesis of endothelial cells. J Food Sci 84: 3284-3295, 2019.

10. Sitarek P, Kowalczyk T, Santangelo S, Bialas AJ, Toma M, Wieczfinska J, Sliwinski T and Skala E: The extract of Leonurus sibiricus transgenic roots with AtPAP1 transcriptional factor induces apoptosis via DNA damage and down regulation of selected epigenetic factors in human cancer cells. Neurochem Res 43: 1363-1370, 2018.

11. de Carvalho MC,Barca FN, Agnez-Lima LP and de Medeirost SR: Evaluation of mutagenic activity in an extract of pepper tree stem bark (schinus terebinthifolius raddi). Environ Mol Mutagen 42: 185-191, 2003.

12. Garcia-Carbonero R and Supko JG: Current perspectives on the clinical experience, pharmacology, and continued development of the camptothecins. Clin Cancer Res 8: 641-661, 2002.

13. Chen AY and Liu LF: DNA topoisomerases: Essential enzymes and lethal targets. Ann Rev Pharmacol Toxicol 34: 191-218, 1994.

14. Pendleton M, Lindsey RH, Felix CA, Grimwade D and Osheroff N: Topoisomerase II and leukemia. Ann N Y Acad Sci 1310: 98-110, 2014

15. Ni W, Zhang S, Jiang B, Ni R, Xiao M, Lu C, Liu J, Qu L, Ni H, Zhang W and Zhou P: Identification of cancer-related gene network in hepatocellular carcinoma by combined bioinformatic approach and experimental validation. Pathol Res Pract 215: $152428,2019$.

16. Liu L, Lin J and He H: Identification of potential crucial genes associated with the pathogenesis and prognosis of endometrial cancer. Front Genet 10: 373, 2019.

17. Lawal AO, Adisa AO and Effiom OA: A review of 640 oral squamous cell carcinoma cases in Nigeria. J Clin Exp Dent 9: e767-e771, 2017.

18. Livak KJ and Schmittgen TD: Analysis of relative gene expression data using real-time quantitative PCR and the 2(-Delta Delta C(T)) method. Methods 25: 402-408, 2001.

19. Li Pei, Yang Cheng, GU Xiaoming, et al: Relationship between the expression of KI-67, VEGF and P16 and the efficacy of pingyangmycin induced chemotherapy in oral squamous cell carcinoma.22: 89-92.

20. Ding HC: Pingyangmycin in the treatment of oral squamous cell carcinoma: Effects and side effects. J Applied Stomatol 1: 3-5, 1998.

21. Siegel R, Ward E, Brawley O and Jemal A: Cancer statistics, 2011: The impact of eliminating socioeconomic and racial disparities on premature cancer deaths. CA Cancer J Clin 61: 212-236, 2011.

22. Peterson DE, Jones JB and Petit RG II: Randomized, placebo-controlled trial of Saforis for prevention and treatment of oral mucositis in breast cancer patients receiving anthracycline-based chemotherapy. Cancer 109: 322-331, 2007.

23. Madan PD, Sequeira PS, Shenoy K and Shetty J: The effect of three mouthwashes on radiation-induced oral mucositis in patients with head and neck malignancies: A randomized control trial. J Cancer Res Ther 4: 3-8, 2008.

24. Iwamoto M, Morikawa T, Narita M, Shibahara T and Katakura A: Investigation of surgical site infections and bacteria detected following neck dissection in patients with oral cancer. Bull Tokyo Dent Coll 61: 1-7, 2020.

25. Li W, Jinyi L, Weiqi F, Xiangjin Z, Liwen R, Shiwei L, Jinhua W, Tengfei $\mathbf{J}$ and Guanhua D: 3-O-acetyl-11-keto- $\beta$-boswellic acid exerts anti-tumor effects in glioblastoma by arresting cell cycle at G2/M phase. J Exp Clin Cancer Res 37: 132, 2018.

26. Liu D, Zhao J, Sun H, He S, Wang J and Zhang Q: Preparation technology of an antibacterial mouthwash. J Food Safety Quality Inspection 10: 638-644, 2019.

27. Chaowuttikul C, Palanuvej $\mathrm{C}$ and Ruangrungsi $\mathrm{N}$ : Pharmacognostic specification, chlorogenic acid content, and in vitro antioxidant activities of Lonicera japonica flowering bud. Pharmacognosy Res 9: 128-132, 2017.

28. Ye LH, Du LJ and Cao J: Fatty acids-based microemulsion liquid chromatographic determination of multiple caffeoylquinic acid isomers and caffeic acid in honeysuckle sample. J Pharm Biomed Anal 171: 22-29, 2019.

29. Chaovanalikit A, Thompson MM and Wrolstad RE: Characterization and quantification of anthocyanins and polyphenolics in bluehHoneysuckle (Lonicera caerulea L.). J Agric Food Chem 52: 848-852, 2004.

30. Zhao Z, Shin HS, Satsu H, Totsuka M and Shimizu M: 5-caffeoylquinic acid and caffeic acid down-regulate the oxidative stress- and TNF-alpha-induced secretion of interleukin-8 from Caco-2 cells. J Agric Food Chem 56: 3863-3868, 2008. 
31. Fang W, Ma Y, Wang J, Yang X, Gu Y and Li Y: In vitro and in vivo antitumor activity of neochlorogenic acid in human gastric carcinoma cells are complemented with ROS generation, loss of mitochondrial membrane potential and apoptosis induction. J BUON 24: 221-226, 2019.

32. De Maria CAB, Moreira Santos MC, José De Lima Dias U and Marana M: Stabilization of soybean oil with heated quercetin and 5-caffeoylquinic acid in the presence of ferric ion. J Agric Food Chem 48: 3935-3938, 2000.

33. Hossain MA, Asa TA, Rahman MM, Uddin S, Moustafa AA, Quinn JMW and Moni MA: Network-based genetic profiling reveals cellular pathway differences between follicular thyroid carcinoma and follicular thyroid adenoma. Int J Environ Res Public Health 17: 1373, 2020.

34. Pabla S, Conroy JM, Nesline MK, Glenn ST, Papanicolau-Sengos A, Burgher B, Hagen J, Giamo V, Andreas J, Lenzo FL, et al: Proliferative potential and resistance to immune checkpoint blockade in lung cancer patients. J Immunother Cancer 7: 27, 2019.

35. Xue JM, Liu Y, Wan LH and Zhu YX: Comprehensive analysis of differential gene expression to identify common gene signatures in multiple cancers. Med Sci Monit 26: e919953, 2020.

36. Coelho PA, Queiroz-Machado J, Carmo AM, Moutinho-Pereira S, Maiato H and Sunkel CE: Dual role of topoisomerase II in centromere resolution and aurora B activity. PLoS Biol 6: e207, 2008.

37. Ben-Shlomo R: Chronodisruption, cell cycle checkpoints and DNA repair. Indian J Exp Biol 52: 399-403, 2014.

38. Sasaki M, Terabayashi T, Weiss SM and Ferby I: The tumor suppressor MIG6 controls mitotic progression and the G2/M DNA damage checkpoint by stabilizing the WEE1 kinase. Cel Rep 24: 1278-1289, 2018.

39. Satyanarayana A and Kaldis P: Mammalian cell-cycle regulation: Several Cdks, numerous cyclins and diverse compensatory mechanisms. Oncogene 28: 2925-2939, 2009.

40. Qiao L, Zhang Q, Zhang W and Chen JJ: The lysine acetyltransferase GCN5 contributes to human papillomavirus oncoprotein E7-induced cell proliferation via up-regulating E2F1. J Cell Mol Med 22: 5333-5345, 2018

41. Fan X and Chen JJ: Role of Cdk1 in DNA damage-induced G1 checkpoint abrogation by the human papillomavirus E7 oncogene. Cell Cycle 13: 3249-3259, 2014.

42. Thorenoor N, Faltejskova-Vychytilova P, Hombach S, Mlcochova J, Kretz M, Svoboda M and Slaby O: Long non-coding RNA ZFAS1 interacts with CDK1 and is involved in p53-dependent cell cycle control and apoptosis in colorectal cancer. Oncotarget 7: 622-637, 2016.
43. Kulisic-Bilusic T, Schnäbele K, Schmöller I, Dragovic-Uzelac V, Krisko A, Dejanovic B, Milos M and Pifat G: Antioxidant activity versus cytotoxic and nuclear factor kappa B regulatory activities on HT-29 cells by natural fruit juices. Eur Food Res Technol 228: 417-424, 2009.

44. Gao XH, Zhang SD, Wang LT, Yu L, Zhao XL, Ni HY, Wang YQ, Wang JD, Shan CH and Fu YJ: Anti-inflammatory effects of neochlorogenic acid extract from mulberry leaf (Morus alba L.) against LPS-stimulated inflammatory response through mediating the AMPK/Nrf2 signaling pathway in A549 cells. Molecules 25: 1385, 2020.

45. Li C, Huang G, Tan F, Zhou X, Mu J, Zhao X and Giaouris E: In vitro analysis of antioxidant, anticancer, and bioactive components of Apocynum venetum tea extracts. J Food Quality 2019: $1-13,2019$.

46. Merrill CL, Ni H, Yoon LW, Tirmenstein MA, Narayanan P, Benavides GR,Easton MJ, Creech DR, Hu CX, McFarland DC, et al: Etomoxir-induced oxidative stress in HepG2 cells detected by differential gene expression is confirmed biochemically. Toxicol Sci 68: 93-101, 2002.

47. Xiao $\mathrm{H}, \mathrm{Xu} \mathrm{D}$, Chen $\mathrm{P}$, Zeng $\mathrm{G}$, Wang $\mathrm{X}$ and Zhang $\mathrm{X}$ : Identification of five genes as a potential biomarker for predicting progress and prognosis in adrenocortical carcinoma. J Cancer 9: 4484-4495, 2018.

48. Zhou Z, Li Y, Hao H, Wang Y, Zhou Z, Wang Z and Chu X: Screening hub genes as prognostic biomarkers of hepatocellular carcinoma by bioinformatics analysis. Cell Transplant 28 (Suppl 1): S76-S86, 2019.

49. Zhao ZW, Fan XX, Yang LL, Song JJ, Fang SJ, Tu JF, Chen MJ, Zheng LY, Wu FZ, Zhang DK, et al: The identification of a common different gene expression signature in patients with colorectal cancer. Math Biosci Eng 16: 2942-2958, 2019.

50. Pan Z, Li L, Fang Q, Qian Y, Zhang Y, Zhu J, Ge M and Huang P: Integrated bioinformatics analysis of master regulators in anaplastic thyroid carcinoma. Biomed Res Int 2019: 9734576, 2019.

51. Zhu X, Wang D, Lin Q, Wu G, Yuan S, Ye F and Fan Q: Screening key lncRNAs for human rectal adenocarcinoma based on lncRNA-mRNA functional synergistic network. Cancer Med 8: 3875-3891, 2019

52. Menon DR, Luo Y, Arcaroli JJ, Liu S, KrishnanKutty LN, Osborne DG, Li Y, Samson JM, Bagby S, Tan AC, et al: CDK1 interacts with Sox2 and promotes tumor initiation in human melanoma. Cancer Res 78: 6561-6574, 2018.

53. Lim S and Kaldis P: Cdks, cyclins and CKIs: Roles beyond cell cycle regulation. Development 140: 3079-3093, 2013.

54. Gan W, Zhao H, Li T, Liu K and Huang J: CDK1 interacts with iASPP to regulate colorectal cancer cell proliferation through p53 pathway. Oncotarget 8: 71618-71629, 2017. 